\title{
Una aproximación sistémica al manejo costero integrado de playas turísticas mexicanas
}

\section{A Systemic Approach to Integrated Coastal Management of Mexican Tourist Beaches}

\author{
Olga Lidia Jiménez Arenas* (D) https://orcid.org/0000-0002-7738-3674 \\ Ricardo Tejeida Padilla** (i) https://orcid.org/0000-0003-4882-8096 \\ Jorge Armando Rojas Ramírez ${ }^{* *}$ (D) https://orcid.org/0000-0002-0779-1242 \\ Ana Lilia Coria Páez ${ }^{* * * *}$ (1) https://orcid.org/0000-0003-0309-8528
}

\begin{abstract}
Resumen
El propósito de esta investigación es mostrar cómo la adopción del concepto manejo costero integrado en la política costera mexicana ha repercutido en la integración interinstitucional. Además, se estudia el influjo de la participación local en la conformación y activación de comités de playas limpias integrados por el gobierno, el sector privado y la sociedad. Puesto que se necesitan estudios locales que permitan evaluar esta política, se seleccionó Puerto Escondido como ejemplo de cambio a partir de las modificaciones en la política costera mexicana. Se usó la metodología de sistemas suaves y se realizó un diagnóstico mediante la visión de los comités de playas limpias. Como resultado se observó que la política costera avanza hacia una integración entre el gobierno y la sociedad, y sin embargo se requieren mecanismos que promuevan una mayor participación social. La presente investigación se limita a interpretar la perspectiva de dichos comités.

Palabras clave: manejo costero integrado; método sistémico; participación local.
\end{abstract}

\begin{abstract}
The purpose of this research is to show the way in which the integrated coastal management concept in Mexican coastal policy has had an impact on inter-institutional integration. In addition, the influence of local participation on the formation and activation of clean beaches committees integrated by the government, the private sector, and the society is studied. Due to the need for regional studies to evaluate this policy, it is considered Puerto Escondido as an example of change, based on the modifications made to the Mexican coastal policy. The soft systems methodology was used to integrate the vision of the clean beaches committees in a diagnosis. As a result, it is observed that coastal policy is moving towards the government and society integration. However, there is still a need for mechanisms to increase social participation. This work is limited to interpret the perspective of the involved clean beaches committees.

Keywords: integrated coastal management; systemic approach; local participation.
\end{abstract}

Cómo citar: Jiménez Arenas, O. L., Tejeida Padilla, R., Rojas Ramírez, J. A., y Coria Páez, A. L. (2020). Una aproximación sistémica al manejo costero integrado de playas turísticas mexicanas. región y sociedad, 32, el 350. doi: I 0.22 I 98/rys2020/32/I350

* Instituto Politécnico Nacional, Grupo de Investigación en Sistémica y Turismo (GIST). Avenida Miguel Bernard Núm. 39 ,

La Escalera, Gustavo A. Madero, C. P. 07630, Ciudad de México, México. Correo electrónico: lidia.arenas@outlook.com

** Autor para correspondencia. Instituto Politécnico Nacional, Escuela Superior de Turismo, Grupo de Investigación en Sistémica y Turismo (GIST). Avenida Miguel Bernard Núm. 39, La Escalera, Gustavo A. Madero, C. P. 07630, Ciudad de México, México. Correo electrónico: rtejeidap@ipn.mx

*** Instituto Politécnico Nacional, Escuela Superior de Ingeniería Mecánica y Eléctrica, Unidad Zacatenco, Grupo de Investigación en Sistémica y Turismo (GIST). Unidad Profesional Adolfo López Mateos, Gustavo A. Madero, C. P. 07738, Ciudad de México, México. Correo electrónico: jrojasr@ipn.mx

**** Instituto Politécnico Nacional, Escuela Superior de Comercio y Administración, Unidad Tepepan, Grupo de Investigación en Sistémica y Turismo (GIST). Anillo Periférico Sur Manuel Gómez Morín Núm. 4863, Ampliación Tepepan, C. P. 16020, Ciudad de México, México. Correo electrónico: acoria@ipn.mx 


\section{Introducción}

Las costas son esenciales para los humanos. Pueden proveer servicios ambientales de importancia ecológica, social y económica (Muñoz y Bail, 2017). Sin embargo, el sector turístico tradicional de sol y playa que las explota se caracteriza por un uso inadecuado del suelo, la construcción invasiva de inmuebles, la masificación de visitantes, la eliminación de la cubierta vegetal -que ha derivado en contaminación hídrica-, la ineficiencia en el tratamiento de aguas residuales, el aumento de la vulnerabilidad ante riesgos naturales y, en algunos casos, la erosión de la línea costera (Alves, Rigall, Ballester, Benavante y Ferreira, 2015; Calçada de Lamare Leite, 2017; Lozoya, Sardá y Jiménez, 2014; Organización para la Cooperación y el Desarrollo Económico [OCDE], 2017; Pulido y López, 2016).

La afectación ambiental de las costas amenaza los beneficios que proveen estos espacios. De acuerdo con el Banco de Desarrollo de América Latina (CAF, 2017), se necesitan mares y ecosistemas saludables para garantizar una actividad económica competitiva y sostenible en un contexto de cambio climático y aumento de la población mundial. Para México, la salud costera es fundamental, ya que, de sus 32 entidades federativas, 17 tienen un frente litoral. En total son $11122 \mathrm{~km}$ de costa (Comisión Intersecretarial para el Manejo Sustentable de Mares y Costas [CIMARES], 2012b). Ahí habita alrededor de 15\% de la población del país (Instituto Nacional de Estadística y Geografía [INEGI], 2018 y 2019; Secretaría de Medio Ambiente y Recursos Naturales [SEMARNAT], 2019). Se ha observado un crecimiento derivado del flujo migratorio por la oferta laboral del sector turístico. En el periodo 2013-2017, Cancún, Acapulco y Veracruz recibieron el mayor flujo migratorio (Consejo Nacional de Población, 2018).

Tanto las grandes ciudades turísticas costeras como las ciudades de menor dimensión, como Puerto Escondido, Oaxaca, han sufrido afectaciones ambientales debido a contaminación, a un tratamiento inadecuado de aguas residuales, a rellenos sanitarios fuera de norma y a fauna nociva (Comité de Información de la Secretaría de Turismo [SECTUR], 2013; Jiménez, Tejeida, Sáenz y Oliva, 2019).

El problema ambiental que enfrentan los ecosistemas costeros está cambiando la forma de gestionar sus recursos. En el periodo de 1980-2000 se prestaba especial atención al aspecto económico obviando las peculiaridades ecológicas y sociales de cada espacio. Pero ahora el objetivo es lograr el uso sustentable de las costas (Yáñez, Day y Reyes, 2013).

Los esfuerzos de diferentes países para controlar el impacto de la interacción hombre/naturaleza se han centrado en modificar las políticas públicas para orientarlas a transitar de un enfoque sectorial hacia un manejo costero integrado $(\mathrm{MCl})$. Éste promueve el uso sustentable de mares y costas mediante la adopción de políticas públicas y programas o proyectos gubernamentales que incorporan la academia, el sector privado y la comunidad (Avellar, García y Jara, 2014; Grupo de Expertos sobre los Aspectos Científicos de la Protección del Medio Marino [GESAMP], 1969 y 1999; Organización de las Naciones Unidas para la Educación, la Ciencia y la Cultura [UNESCO], 2017). En este sentido, los esfuerzos de los países se han centrado en la revisión de su marco legal, en el 
establecimiento de instrumentos operativos medioambientales o relacionados con el uso del suelo y en fomentar la participación pública y la sustentabilidad (Barragán, 2012).

México ha buscado involucrar tanto al gobierno como a la sociedad, promoviendo una coordinación institucional, así como la idea de una gestión que sea capaz de ajustarse a los cambios del entorno (CIMARES, 2018). La presente investigación plantea una revisión, a modo de diagnóstico, de esta política y su influencia en la gobernanza de las playas turísticas, como Puerto Escondido, Oaxaca. La aproximación a este tema se hace mediante el método sistémico debido a que éste promueve la visión holística, la integración y la participación en el estudio de sistemas de actividad humana. Esto, además de un acercamiento a la problemática en cuestión, es un punto de partida para implementar acciones de mejora.

\section{Gestión de espacios costeros desde la integralidad}

Desde la década de 1970, se introdujo el concepto de manejo costero integrado $(\mathrm{MCl})$ como guía para la gestión sustentable de las costas y mares (Reis, Stojanovic y Smith, 2014). Su objetivo es motivar la adopción de políticas públicas que integren el gobierno, la comunidad, el sector privado y la ciencia, a fin de mejorar la calidad de vida de las comunidades que dependen de los recursos costeros y mantener la diversidad y productividad biológica de esos ecosistemas (Avellar, García y Jara, 2014; GESAMP, 1969 y 1999). El MCI ha sido reconocido en la Conferencia de Naciones Unidas sobre el Medio Ambiente y el Desarrollo como la herramienta adecuada para garantizar el desarrollo sostenible de las áreas costeras (UNESCO, 2017).

$\mathrm{El} \mathrm{MCl}$ se designa con diversos nombres, entre ellos: gestión integrada de zonas costeras; manejo integrado de zonas costeras; manejo integrado de áreas costeras; y manejo integrado de áreas marinas y costeras (Avellar, García y Jara, 2014; Derrick y Xue, 2017; Farinós y Cortés, 2010; GESAMP, 1969 y 1999; Portman, Steves, Le y Khan, 2012; Reis, Stojanovic y Smith, 2014; Secretaría de la Convención de Ramsar, 2010; Uehara y Mineo, 2017; Uehara, Niu, Chen, Ota y Nakagami, 2016).

$\mathrm{El} \mathrm{MCl}$ es un proceso continuo, dinámico y adaptable de cinco pasos. Dependiendo de las necesidades, este ciclo puede alterarse o repetirse (Avellar, García y Jara, 2014; GESAMP, 1999, pp. 13-17):

1. Identificación y evaluación de asuntos claves.

2. Preparación del programa: implica definir objetivos específicos tras análisis, debates e implementación a escala piloto, por lo que puede tomar años.

3. Adopción formal y financiamiento.

4. Implementación.

5. Evaluación: es la etapa de mayor aprendizaje. Sin embargo, es también la más omitida o realizada de manera superficial. 
Los acuerdos que se deriven de un proceso de $\mathrm{MCl}$ deben ser aceptados de manera formal dentro de una ley o por un decreto para darles identidad institucional y continuidad. Estos acuerdos pueden convertirse en programas o ser la base para crear organizaciones independientes (GESAMP, 1969 y 1999). El fin es establecer nexos entre las actividades sectoriales para fortalecer y armonizar la gestión sustentable de costas (Secretaría de la Convención de Ramsar, 2010; Uehara et al., 2016). Las metas del MCl dependen de las limitaciones físicas, sociales, económicas, jurídicas y administrativas del sistema donde se desee aplicarlo, ya que requiere fuertes inversiones de dinero y tiempo.

El concepto de $\mathrm{MCl}$ se ha aplicado en Bélgica, India, Israel, Italia, Portugal, Suecia, Vietnam y Reino Unido, por medio de mecanismos de integración, como la creación de comisiones, la propuesta de ordenamientos marinos y terrestres y el establecimiento de jerarquías. Sin embargo, no se ha tenido el éxito esperado debido al incumplimiento de las normativas, a retrasos en la planeación de un nivel superior que dan como resultado políticas o planes obsoletos, a la escasa incorporación de conocimiento científico, a un enfoque rígido de arriba hacia abajo que no considera las condiciones locales y a la falta de integración a escala local (Cappucci, Scarcella, Rossi y Taramelli, 2011; Portman et al., 2012).

En América Latina también se ha retomado este concepto. Sin embargo, de acuerdo con Barragán (2012), aunque Costa Rica, Brasil, Colombia, Chile, Cuba, Puerto Rico, Uruguay y México, por ejemplo, han implementado esfuerzos en política, en normatividad y en competencias e instituciones a fin de llevar a cabo un $\mathrm{MCl}$, no han logrado alcanzar una gestión equilibrada de las zonas costeras, puesto que aún se perciben insuficiencias en ciertos factores, como políticas, competencias, formación, capacitación e información que impiden alcanzar este objetivo.

\section{Política de costas en México}

La franja costera de México representa $21 \%$ de la superficie del territorio nacional. De acuerdo con la Política Nacional de Mares y Costas (CIMARES) (véase figura 1):

La zona costera es el espacio geográfico de interacción mutua entre el medio marino, el medio terrestre y la atmósfera, comprendido por: a) una porción continental definida por 265 municipios costeros; 150 con frente de playa y 114 sin acceso al mar, pero con influencia costera alta y media (por ejemplo, vegetación costera); b) una porción marina definida a partir de la plataforma continental delimitada por la isóbata de los 200 metros, y c) una porción insular representada por las islas nacionales. (CIMARES, 2018)

En el periodo 2003-2016, los estados costeros contribuyeron en $43 \%$ al producto interno bruto nacional (CIMARES, 2018). Las actividades económicas que predominan en esta zona son: turismo, hidrocarburos, minería marina, puertos 


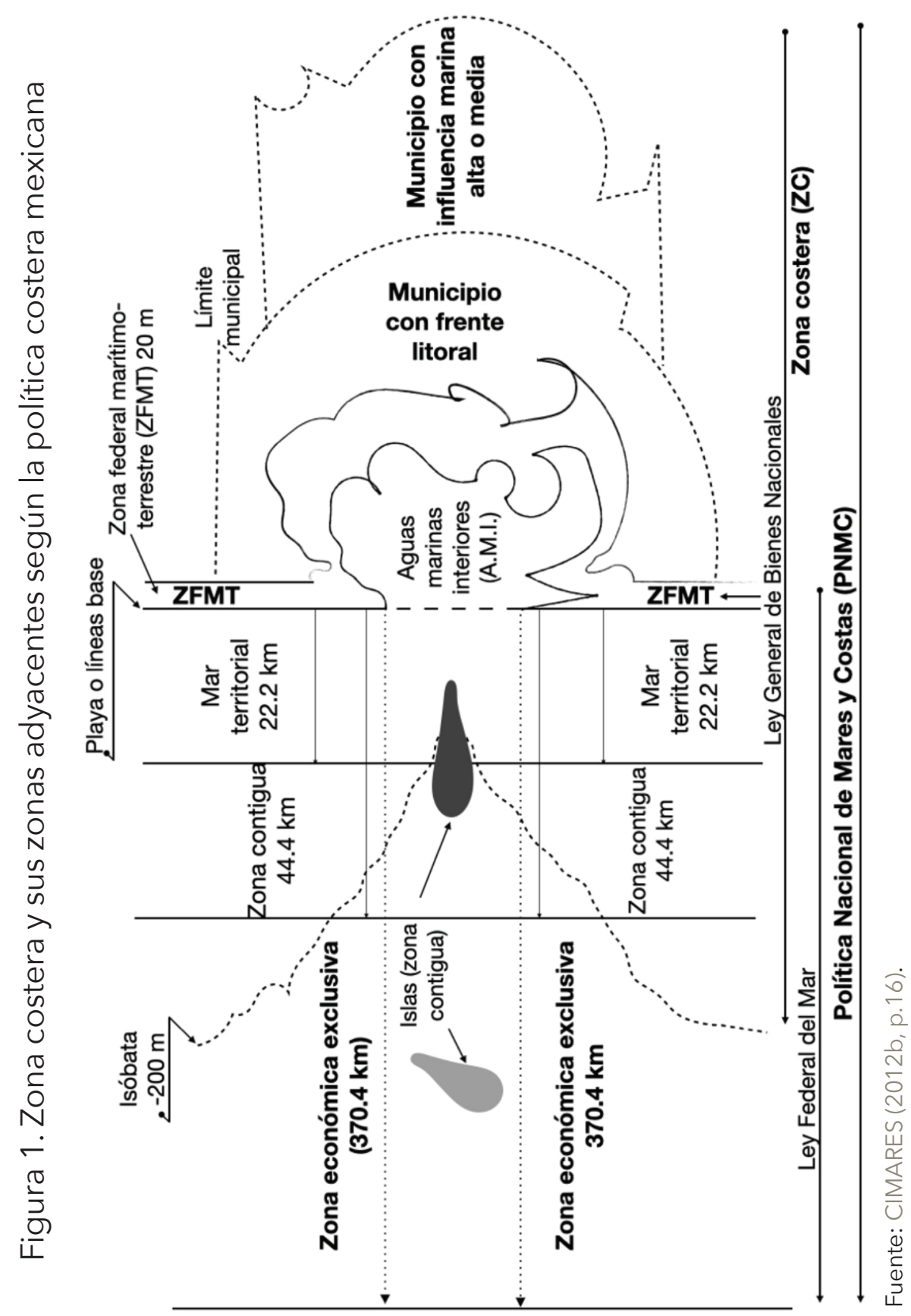


y marina mercante, pesca y acuacultura (CIMARES, 2012a; Congreso General de los Estados Unidos Mexicanos, 2004).

Existe un amplio marco regulatorio conformado por leyes, reglamentos y normas para abordar los temas costeros (véanse tabla 1 y 2). Estas leyes se enfocan en regular el uso y disposición de los recursos costeros, sus afectaciones ambientales y las actividades socioeconómicas que en ellos se desarrollan. Su aplicación se complementa y clarifica con los reglamentos de cada una de estas leyes, en los que se destaca el reglamento para el uso y aprovechamiento del mar territorial, de las vías navegables, de las playas, de la zona federal marítimo-terrestre y de los terrenos ganados al mar.

Tabla 1. Marco legal de las zonas costeras

\begin{tabular}{|c|c|}
\hline Ordenamiento & Objetivo \\
\hline Ley General de Bienes Nacionales & Regular los bienes propiedad de la Nación \\
\hline $\begin{array}{l}\text { Ley General de Equilibrio } \\
\text { Ecológico y Protección } \\
\text { al Ambiente (LGEEPA) }\end{array}$ & $\begin{array}{l}\text { Preservar y restaurar el ambiente } \\
\text { y procurar el equilibrio ecológico. }\end{array}$ \\
\hline Ley de Aguas Nacionales (LAN) & $\begin{array}{c}\text { Regular el aprovechamiento y distribución de las } \\
\text { aguas nacionales para asegurar su calidad en el } \\
\text { marco del desarrollo integral sustentable. }\end{array}$ \\
\hline Ley Federal del Mar & Normar las zonas marinas mexicanas. \\
\hline Ley de Puertos & $\begin{array}{c}\text { Regular la construcción y operación de puertos, } \\
\text { terminales y marinas. }\end{array}$ \\
\hline $\begin{array}{l}\text { Ley General de Pesca y } \\
\text { Acuacultura Sustentables }\end{array}$ & $\begin{array}{c}\text { Regular el aprovechamiento de los recursos } \\
\text { pesqueros y acuícolas de la nación. }\end{array}$ \\
\hline $\begin{array}{c}\text { Ley de Navegación y Comercio } \\
\text { Marítimo }\end{array}$ & $\begin{array}{c}\text { Regular las embarcaciones y sus actividades } \\
\text { comerciales y recreativas. }\end{array}$ \\
\hline Ley de Cambio Climático & Garantizar el derecho a un medio ambiente sano. \\
\hline $\begin{array}{l}\text { Ley de Vertimientos en las Zonas } \\
\text { Marinas Mexicanas }\end{array}$ & $\begin{array}{c}\text { Controlar y prevenir la contaminación o alteración } \\
\text { del mar por vertimientos en las zonas marinas } \\
\text { mexicanas. }\end{array}$ \\
\hline Ley de Derechos & $\begin{array}{c}\text { Regular el cobro de derechos por el uso } \\
\text { y aprovechamiento de los bienes nacionales. }\end{array}$ \\
\hline $\begin{array}{l}\text { Ley General de Asentamientos } \\
\text { Humanos, Ordenamiento } \\
\text { Territorial y Desarrollo Urbano }\end{array}$ & Regular los asentamientos humanos. \\
\hline Ley General de Vida Silvestre & $\begin{array}{c}\text { Proteger y conservar especies nativas } \\
\text { de vida silvestre. }\end{array}$ \\
\hline $\begin{array}{l}\text { Ley General de Desarrollo } \\
\text { Forestal Sustentable }\end{array}$ & $\begin{array}{c}\text { Regular y fomentar el manejo integral } \\
\text { y sustentable de los ecosistemas forestales. }\end{array}$ \\
\hline Ley General de Turismo & Regular las actividades turísticas en el país. \\
\hline
\end{tabular}

Fuente: elaboración propia con base en el marco legislativo mexicano. 
Además, se cuentan con Normas Oficiales Mexicanas (NOM), de cumplimiento obligatorio, para el aprovechamiento sustentable de los recursos naturales. Así mismo se promueven Normas Mexicanas (NMX), de cumplimiento voluntario, que promueven el saneamiento y ordenamiento de las playas (véase tabla 2).

Tabla 2. Normas aplicables a la zona costera

\begin{tabular}{|c|c|}
\hline Norma & Descripción \\
\hline NOM-022-SEMARNAT-2003 & $\begin{array}{l}\text { Establece las especificaciones para la conservación, } \\
\text { el aprovechamiento sustentable y la restauración } \\
\text { de los humedales costeros en zonas de manglar. }\end{array}$ \\
\hline NOM-143-SEMARNAT-2003 & $\begin{array}{l}\text { Establece las especificaciones ambientales para el } \\
\text { manejo de agua congénita asociada a hidrocarburos }\end{array}$ \\
\hline NOM-009-SAG/PESC-2015 & $\begin{array}{c}\text { Establece las medidas necesarias para determinar } \\
\text { temporadas de veda en zonas de captura } \\
\text { y de pesca deportiva. }\end{array}$ \\
\hline NOM-017-PESC-1994 & $\begin{array}{l}\text { Regula la pesca deportivo-recreativa } \\
\text { en las aguas de jurisdicción federal. }\end{array}$ \\
\hline NOM-001-SEMARNAT-1996 & $\begin{array}{l}\text { Establece los límites máximos permisibles } \\
\text { de contaminantes en las descargas de aguas } \\
\text { residuales en aguas y bienes nacionales, con el } \\
\text { objeto de proteger su calidad y posibilitar sus usos. }\end{array}$ \\
\hline NOM-002-SEMARNAT-1996 & $\begin{array}{l}\text { Establece los límites máximos permisibles de } \\
\text { contaminantes en las descargas de aguas residuales } \\
\text { a los sistemas de alcantarillado urbano o municipal. }\end{array}$ \\
\hline NOM-162-SEMARNAT-2012 & $\begin{array}{c}\text { Especificaciones para la protección, recuperación } \\
\text { y manejo de las poblaciones de las tortugas marinas } \\
\text { en su hábitat de anidación. }\end{array}$ \\
\hline NOM-146-SEMARNAT-2017 & $\begin{array}{l}\text { Establece la metodología para identificar } \\
\text { y representar cartográficamente la Zona Federal } \\
\text { Marítimo Terrestre y Terrenos Ganados al Mar. }\end{array}$ \\
\hline NMX-AA-120-SCFI-2016 & $\begin{array}{c}\text { Establece los requisitos para certificar una playa } \\
\text { como "playa limpia". }\end{array}$ \\
\hline
\end{tabular}

Fuente: elaboración propia con base en el marco legislativo mexicano.

Sin embargo, este amplio marco regulatorio presenta sobrerregulación, incongruencias y vacíos entre instrumentos jurídicos, desarticulación de competencias y bajo nivel de vigilancia (CIMARES, 2012b). Esto se atribuye a que la gestión de las costas mexicanas se ha distribuido en diversas dependencias a escalas federal, estatal y municipal, lo cual ha derivado en diferentes ordenamientos pesqueros, acuícolas, turísticos y territoriales que inhiben la articulación y coordinación entre las instituciones y limitan la vigilancia del cumplimiento de la normativa y del financiamiento (Nava, Arenas y Martins, 2017). 
De acuerdo con la Ley de Bienes Nacionales, en México, las zonas de playas, la Zona Federal Marítimo Terrestre (ZFMT), los terrenos ganados al mar, así como los depósitos formados con aguas marinas son administrados, principalmente, por la Secretaría de Medio Ambiente y Recursos Naturales (SEMARNAT) a través de la Dirección General de Zona Federal Marítimo Terrestre y Ambientes Costeros. Sin embargo, la cantidad de instituciones involucradas incrementa según el tipo y el número de actividades socioeconómicas desarrolladas, así como por el interés ambiental, económico, político o social depositado en cierta área (CIMARES, 2012a; Nava, Arenas y Martins, 2017).

Las instituciones involucradas son organismos nacionales, internacionales, regionales, estatales y municipales.

a) Organismos nacionales:

(1) Secretarías de Estado: Secretaría de Medio Ambiente y Recursos Naturales; Secretaría de Marina; Secretaría de Turismo; Secretaría de Desarrollo Agrario, Territorial y Urbano; Secretaría de Agricultura, Ganadería, Desarrollo Rural, Pesca y Alimentación.

(2) Dependencias y órganos federales: Comisión Nacional del Agua; Comisión Nacional para el Conocimiento y Uso de la Biodiversidad; Comisión Intersecretarial para el Manejo de Mares y Costas (CIMARES); Comisión Federal para la Protección contra Riesgos Sanitarios; Comisión Nacional de Acuacultura y Pesca; Comisión Nacional de Áreas Naturales Protegidas; Fondo Nacional de Fomento al Turismo; Instituto de Ecología; Instituto Nacional de Ecología y Cambio Climático; Instituto Nacional de Pesca.

b) Dependencias estatales y regionales: cada dependencia federal cuenta con representantes a escalas estatal y regional encargados de vigilar el cumplimiento de la normativa correspondiente a las zonas costeras. Además, se han creado consejos de cuenca que actúan en cada región para vigilar las cuencas del país.

c) Organismos municipales: comités de playas limpias (CPL), autoridades municipales y regidurías como salud, ecología, turismo.

d) Organismos internacionales: México forma parte de organizaciones como Naciones Unidas (ONU) y ha firmado acuerdos, como el Programa 21, que influyen en el establecimiento de políticas públicas y en programas y acciones a favor del entorno costero, por lo que estos organismos se consideran reguladores.

Debido a la diversidad de actividades socioeconómicas y al número de dependencias involucradas en la gestión costera mexicana, el concepto de integración es importante. Su aparición formal en la política costera de México ocurrió en el año 2000 con la propuesta de la Estrategia Ambiental para la Gestión Integrada de la Zona Costera de México. En 2008, la integración entre instituciones involucradas en la gestión costera se materializó con la creación de la Comisión Intersecretarial para el Manejo Sustentable de Mares y Costas (CIMARES), que estableció, en 2012, la Política Nacional de Mares y Costas aún vigente -véase tabla 3- (CIMARES, 2012b; Sampedro, Ávila, Arredondo, Espejel, 2015). 
Tabla 3. Síntesis de la Política Nacional de Mares y Costas de México

\begin{tabular}{|c|c|c|}
\hline Principios rectores & Objetivos & Estrategias \\
\hline $\begin{array}{l}\text { Visión integral: involucrar } \\
\text { gobierno y sociedad, } \\
\text { intereses públicos y } \\
\text { privados, así como } \\
\text { conocimiento } \\
\text { multidisciplinario. } \\
\text { Coordinación institucional. } \\
\text { Busca articular acciones y } \\
\text { programas institucionales, } \\
\text { tanto vertical } \\
\text { (intrainstitucional) como } \\
\text { horizontalmente } \\
\text { (interinstitucional), a fin } \\
\text { de evitar duplicidad de } \\
\text { funciones y la sobreposición }\end{array}$ & $\begin{array}{l}\text { Contribuir a mejorar } \\
\text { las condiciones de } \\
\text { vida de las } \\
\text { poblaciones costeras } \\
\text { por medio del } \\
\text { aprovechamiento } \\
\text { sustentable de los } \\
\text { recursos que ofrecen } \\
\text { las zonas marinas } \\
\text { y costeras, y } \\
\text { procurando una } \\
\text { distribución más } \\
\text { equitativa de la } \\
\text { riqueza que en ellas } \\
\text { se genera. }\end{array}$ & $\begin{array}{c}\text { Impulsar y fomentar: } \\
\text { El aprovechamiento sustentable } \\
\text { de los recursos naturales. } \\
\text { La operación de plantas para el } \\
\text { tratamiento de aguas residuales y } \\
\text { sitios de disposición de residuos. } \\
\text { Programas de desarrollo urbano en } \\
\text { municipios costeros. } \\
\text { Acciones para reducir la } \\
\text { vulnerabilidad en materia de cambio } \\
\text { climático. } \\
\text { Áreas potenciales para reubicar } \\
\text { asentamientos humanos y/o } \\
\text { infraestructura urbana situada } \\
\text { en zonas de riesgo. }\end{array}$ \\
\hline $\begin{array}{c}\text { de atribuciones. } \\
\text { Adaptativa. Una política } \\
\text { capaz de evolucionar } \\
\text { y ajustarse continuamente. } \\
\text { Transparente y participativa. } \\
\text { Política basada en } \\
\text { información oportuna y } \\
\text { precisa que se difunde y que } \\
\text { involucra la participación y } \\
\text { la consulta pública para la } \\
\text { toma de decisiones. } \\
\text { Sustentada en la mejor } \\
\text { información disponible y } \\
\text { promotora de la generación } \\
\text { e integración de información } \\
\text { v datos. Utiliza evidencia. }\end{array}$ & $\begin{array}{c}\text { Fortalecer las } \\
\text { economías locales, } \\
\text { mejorar la } \\
\text { competitividad } \\
\text { regional y contribuir a } \\
\text { la nacional, } \\
\text { incentivando las } \\
\text { actividades } \\
\text { económicas y } \\
\text { productivas r } \\
\text { esponsables } \\
\text { con el medio } \\
\text { ambiente marino } \\
\text { y costero. }\end{array}$ & $\begin{array}{c}\text { Promover e impulsar: } \\
\text { Estrategias de política exterior en } \\
\text { coordinación intersectorial con las } \\
\text { dependencias y entidades } \\
\text { involucradas en la gestión de las } \\
\text { zonas marinas mexicanas. } \\
\text { Programas con criterios ambientales, } \\
\text { económicos y sociales para el } \\
\text { desarrollo y aprovechamiento sustent- } \\
\text { able de las zonas costeras y marinas. } \\
\text { Esquemas de certificación de los } \\
\text { procesos y actividades productivas } \\
\text { de los municipios costeros. } \\
\text { Energías renovables en los estados } \\
\text { costeros. }\end{array}$ \\
\hline $\begin{array}{c}\text { información sistemática y } \\
\text { con rigor científico que dé } \\
\text { certidumbre a la toma de } \\
\text { decisiones. } \\
\text { Legalmente fundamentada. } \\
\text { Se apoya en la } \\
\text { normatividad existente } \\
\text { y busca la adecuación } \\
\text { de instrumentos legales. } \\
\text { Orientada al fortalecimiento } \\
\text { del federalismo. Promueve } \\
\text { el desarrollo sustentable } \\
\text { desde el ámbito de los } \\
\text { municipios costeros. }\end{array}$ & $\begin{array}{l}\text { Asegurar que la } \\
\text { estructura y función } \\
\text { de los ecosistemas } \\
\text { marino-costeros no } \\
\text { sufran alteraciones } \\
\text { irreversibles y en su } \\
\text { caso se recupere su } \\
\text { resiliencia y mantener, } \\
\text { inducir o incrementar } \\
\text { los bienes y servicios } \\
\text { que prestan y su } \\
\text { calidad paisajística. }\end{array}$ & $\begin{array}{c}\text { Promover y participar en: } \\
\text { El Inventario Nacional Costero que } \\
\text { contribuya a la evaluación } \\
\text { de la salud oceánica. } \\
\text { Programas de ordenamiento } \\
\text { ecológico regionales y marinos. } \\
\text { La regulación y el ordenamiento } \\
\text { pesquero. } \\
\text { Ordenamiento ecológico } \\
\text { y/o territorial local en los municipios } \\
\text { con frente litoral. } \\
\text { Un Sistema Nacional de Monitoreo } \\
\text { e Información Marina y Costera. } \\
\text { Instrumentar acciones para la } \\
\text { conservación y manejo de los } \\
\text { ecosistemas de manglar y la } \\
\text { biodiversidad en las zonas } \\
\text { marítimo-costeras. } \\
\text { Estudios de peligro y/o atlas de } \\
\text { riesgo para las regiones costeras del } \\
\text { territorio nacional definidas como } \\
\text { sensibles por la autoridad } \\
\text { competente y/o esta Comisión. } \\
\text { Impulsar la ratificación y puesta } \\
\text { en marcha de los compromisos } \\
\text { internacionales signados por México } \\
\text { en materia de mares y costas. }\end{array}$ \\
\hline
\end{tabular}

Fuente: CIMARES (2018). 
Esta política subraya la necesidad de integración a fin de mejorar las condiciones de vida de la población costera, de incentivar la competitividad y la diversificación de las actividades económicas y de fomentar la conservación ambiental de estos entornos. Con esto se pretende enfrentar las amenazas y disminuir la vulnerabilidad de la infraestructura y de la población (CIMARES, 2018). Es importante mencionar que esta política promueve la integración del conocimiento tradicional y de las cosmovisiones de los grupos interesados para la toma de decisiones, con el fin de mejorar la gobernanza de las zonas costeras.

Al respecto, el Programa de Playas Limpias (que inició en 2003), cuyo objetivo es promover el saneamiento de las cuencas, ríos, mares y costas para mejorar la calidad ambiental y productiva de éstos, promueve la formación de comités integrados por dependencias, el sector privado y la sociedad denominados comités de playas limpias (CPL) (Comisión Nacional del Agua, 2018; SEMARNAT, 2018).

Además de estos elementos, la gestión costera mexicana se apoya en el Plan Nacional de Desarrollo, en programas sectoriales o especiales, como la planeación y regulación ambiental de los asentamientos humanos; en el ordenamiento ecológico, turístico y territorial; en el ordenamiento pesquero, acuícola y las zonas de desarrollo turístico sustentable; y en instrumentos económicos y de regulación sanitaria. Así mismo, se consideran instrumentos normativos, como la evaluación del impacto ambiental; las autorizaciones, permisos y concesiones; los instrumentos de identificación de áreas de riesgo y vulnerabilidad y las auditorías ambientales (CIMARES, 2018).

La revisión de la política mexicana sobre zonas costeras permite afirmar que se ha buscado mejorar el aprovechamiento de los recursos costeros a partir de la integración sectorial, económica y social, de la participación ciudadana y del fortalecimiento de la gestión desde el ámbito municipal. Sin embargo, las playas presentan un contexto diverso dependiendo de su orientación económica y de sus características sociopolíticas, por lo que, para entender la influencia de la política de mares y costas mexicana en un entorno costero dado, se debe partir de un diagnóstico específico.

Existen diversas aportaciones sobre gestión de playas que adoptan un enfoque sectorial con la finalidad de comprender las relaciones entre distintos participantes. No obstante, esta perspectiva presenta limitaciones al abordar la pluralidad de intereses que predomina en los espacios turísticos. Alves et al. (2015), Chen y Ning (2016) y Lozoya, Sardá y Jiménez (2014) mencionan que existen distintos enfoques para gestionar las playas, entre los que se destacan el económico, el ambiental y el geográfico. Sin embargo, su carácter integrador es limitado al no concebir la playa como un sistema socio-ecológico ni identificar mecanismos para hacer frente a la pluralidad de intereses y de actividades, así como de actores involucrados, además del desorden que el factor humano puede generar.

Por su parte, Bombana, Conde y Polette (2016), Chapin y Knapp (2015), Mizuta y Vlachopoulou (2017) y Sakurai, Ota y Uehara (2017) proponen que los actores locales sean incluidos en la toma de decisiones y en el proceso para gestionar las playas como un paso para abordar e integrar el pluralismo presente 
en un espacio como el referido. Montaño, Pérez y O (2014) y Soares, Ivars y Gândara (2015) concuerdan en que tratar las playas sólo como un destino turístico consolidado, o sea, una zona que ha alcanzado su madurez como producto, es insuficiente, pues tal postura soslaya aspectos que se relacionan con su complejidad, con procesos entrópicos y de adaptación.

Debido a que las playas son sistemas complejos que poseen múltiples interrelaciones no lineales, actores, componentes y situaciones problemáticas, su estudio tiene que realizarse con una perspectiva ampliada. Por eso se utiliza aquí el Método Sistémico, que permite visualizar un fenómeno a partir de sus elementos y sus relaciones sin soslayar su contexto (Jackson, 2003; Soares, Ivars y Gândara, 2015; Tikkanen, Hujala y Kurttila, 2016). Es decir, permite contextualizar las interacciones hombre/naturaleza de un sistema socio-ecológico.

\section{Metodología}

El Método Sistémico ha sido empleado para estudiar diversas temáticas, entre ellas, las temáticas socioecológicas (Sánchez, Ramírez, Núñez, Cardoso y Rojas, 2019). Dentro de éste existen diversas metodologías y modelos que pueden usarse en el estudio de las zonas costeras. Jackson (2003) propuso la Matriz Contexto-problema que permite ubicar al sistema a estudiar y, en consecuencia, identificar la metodología de mayor pertinencia para su interpretación. De acuerdo con esta matriz, los sistemas pueden ser: 1) simples o complejos y 2) de participación unitaria, pluralista o coercitiva (véase figura 2). Las playas, al estar compuestas por variedad de visiones, son pluralistas y, dada la diversidad de relaciones presentes en la interacción ambiente/sociedad, constituyen un sistema complejo. En consecuencia, los sistemas de playa con fines turísticos pueden entenderse como sistemas complejo-pluralistas.

Figura 2. Matriz Contexto-problema

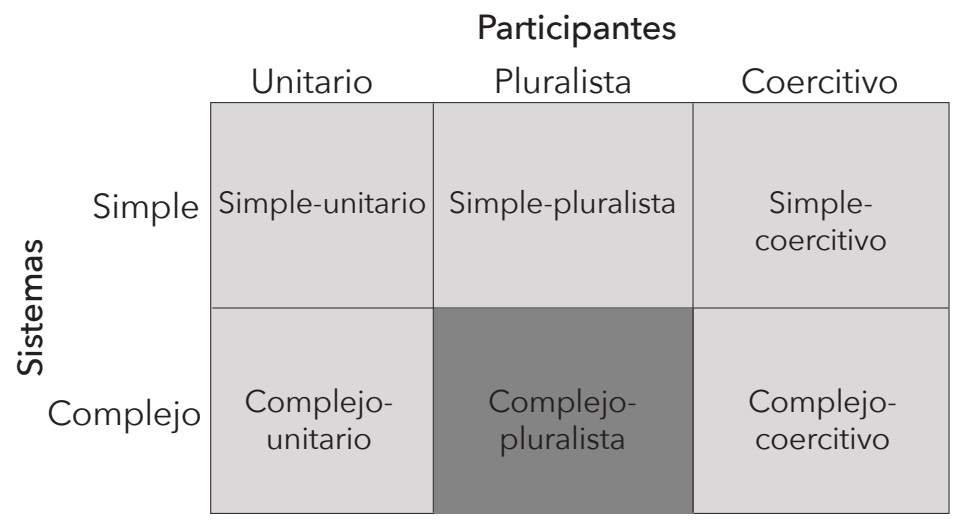

Fuente: Jackson (2003, p. 18). 
De acuerdo con la matriz contexto-problema (Jackson, 2003), los sistemas complejo-pluralistas pueden ser estudiados con la metodología de sistemas suaves (MSS), debido a que ésta permite abordar la complejidad derivada de la pluralidad inherente a los sistemas de actividad humana. Es útil para integrar la perspectiva de los involucrados respecto a un problema, lo que permite generar un diagnóstico desde una visión particular (Checkland, 1999; Fernandes, Barra, Carvalho y Friend, 2015; Jackson, 2003; Tikkanen, Hujala y Kurttila, 2016).

La MSS es una metodología que se basa en la fenomenología y la hermenéutica (Ramírez-Gutiérrez, Cardoso-Castro y Tejeida-Padilla, 2020). Se ha empleado para identificar a los actores que intervienen en un sistema y sus objetivos e intereses, lo cual permite aclarar el papel de cada actor, su función y la visión conjunta de lo que el sistema es y hace (Wang, Lui y Mingers, 2015). Ofrece siete estadios. Los dos primeros consisten en la aclaración de la problemática. Los estadios tres y cuatro promueven la definición del sistema como el deber ser y las actividades mínimas necesarias para alcanzar este propósito. El estadio cinco promueve el contraste de la propuesta con la realidad, a fin de identificar los cambios deseados y factibles para mejorar la situación del sistema bajo estudio (estadio seis). Por último, el estadio siete consiste en la aplicación de dichos cambios. La estructura de esta metodología es flexible; en consecuencia, su aplicación puede partir de diferentes etapas dependiendo de las necesidades de la problemática a tratar.

La MSS permite la integración de diversas perspectivas en la definición de una problemática. Sin embargo, no limita el número de participantes que deben intervenir. Incluso la problemática puede ser explicada a partir de la visión del investigador sistemista (Tejeida, Cruz y Briones, 2016). Desde luego, esto implica una limitación pues, aunque se consideran todos los elementos, los participantes que definen la problemática exponen, desde su perspectiva, la visión de los actores que no participan en la creación del constructo, por lo que se debe tener especial cuidado al seleccionar las fuentes que contribuyen a interpretar y contextualizar la problemática de un sistema en específico.

En el presente trabajo se expone el problema desde la perspectiva de los CPL de los municipios de Puerto Escondido: San Pedro Mixtepec y Santa María Colotepec. Se eligió trabajar con estos actores debido a que son un órgano mixto de apoyo en la gestión de los recursos costeros donde fueron establecidos. Como se mencionó en apartados previos, estos comités fueron creados con el objetivo de contribuir en el saneamiento y en la gestión de los recursos costeros. Su propósito es incorporar en una organización formal la sociedad, el sector privado y el gobierno. Debido a que son órganos mixtos, no mantienen un interés particular en la gestión de estos recursos al no recibir un ingreso directo por esta actividad, a diferencia del sector gubernamental y de los concesionarios. Además, por su permeabilidad, tienen acceso a información tanto gubernamental como del sector privado y de la sociedad.

Además de estas ventajas, se decidió trabajar con los CPL debido a que representan parte de los estatutos de la política costera mexicana al buscar la integración entre gobierno y sociedad, lo que permite dilucidar los resultados de esta política a escala local. La participación de estos comités contribuyó a 
elaborar un diagnóstico en el siguiente orden: 1) estructurar el problema percibido y 2) identificar las relaciones conflictivas. La construcción de estos resultados se consolidó en un periodo de tres años (2017-2020) mediante entrevistas y comunicación constante, sobre todo con los gerentes operativos de los CPL de los municipios de Santa María Colotepec y San Pedro Mixtepec.

Área de estudio

Puerto Escondido (PE) es un destino de sol y playa del estado de Oaxaca. Su oferta turística se compone de pequeñas y medianas empresas y del surf y la pesca deportiva, que son sobre todo demandados por mexicanos (alrededor de 97\% en 2018) (Secretaría de Turismo de Oaxaca, 2019). Este sitio turístico comparte jurisdicción entre dos municipios oaxaqueños: las playas Bacocho, Carrizalillo, Puerto Angelito y Manzanillo pertenecen a la demarcación municipal de San Pedro Mixtepec; y Zicatela, a Santa María Colotepec. En cuanto a la bahía principal, comparten su administración ambos municipios (Jiménez, Tejeida, Sáenz y Oliva, 2019).

PE fue incorporado al Programa de Playas Limpias en 2004 y al Programa de Turismo Sustentable en 2005 debido a problemas ambientales, como: descarga directa de aguas residuales al mar, rellenos sanitarios fuera de norma, contaminación de playas, ausencia de programas de calidad y presencia de fauna errante (como perros) en la zona de playa y en la zona urbana (Comisión Nacional del Agua, 2010; Comité de Información SECTUR, 2013). Tras la integración de PE al Programa de Playas Limpias, se creó primero el Comité de Playas Limpias de San Pedro Mixtepec (CPLSPM) y después el Comité de Playas Limpias de Santa María Colotepec (CPLSMC).

\section{Resultados}

Estructura del problema

Comprender un problema requiere una imagen de éste lo más rica posible; también de la situación en la que es percibido (Checkland, 1993). En este sentido, se procedió a identificar los elementos que intervienen en la gestión de esta zona costera. Este proceso llevó a identificar que PE, como zona costera, es un sistema de interacción entre un medio físico y la sociedad. Estas relaciones están reguladas e influidas por organismos municipales, estatales y nacionales, así como por enfoques y herramientas de influencia costera. Los elementos identificados como parte de la dinámica de PE se describen en la figura 3.

La representación anterior expone lo siguiente:

a) Medio físico: factores como el paisaje, el tipo de dunas, el oleaje y el clima, además de la accesibilidad, influyen en las actividades socioeconómicas que se pueden desarrollar, como la pesca deportiva y el surf (Zicatela tiene olas de hasta dos metros de altura). 


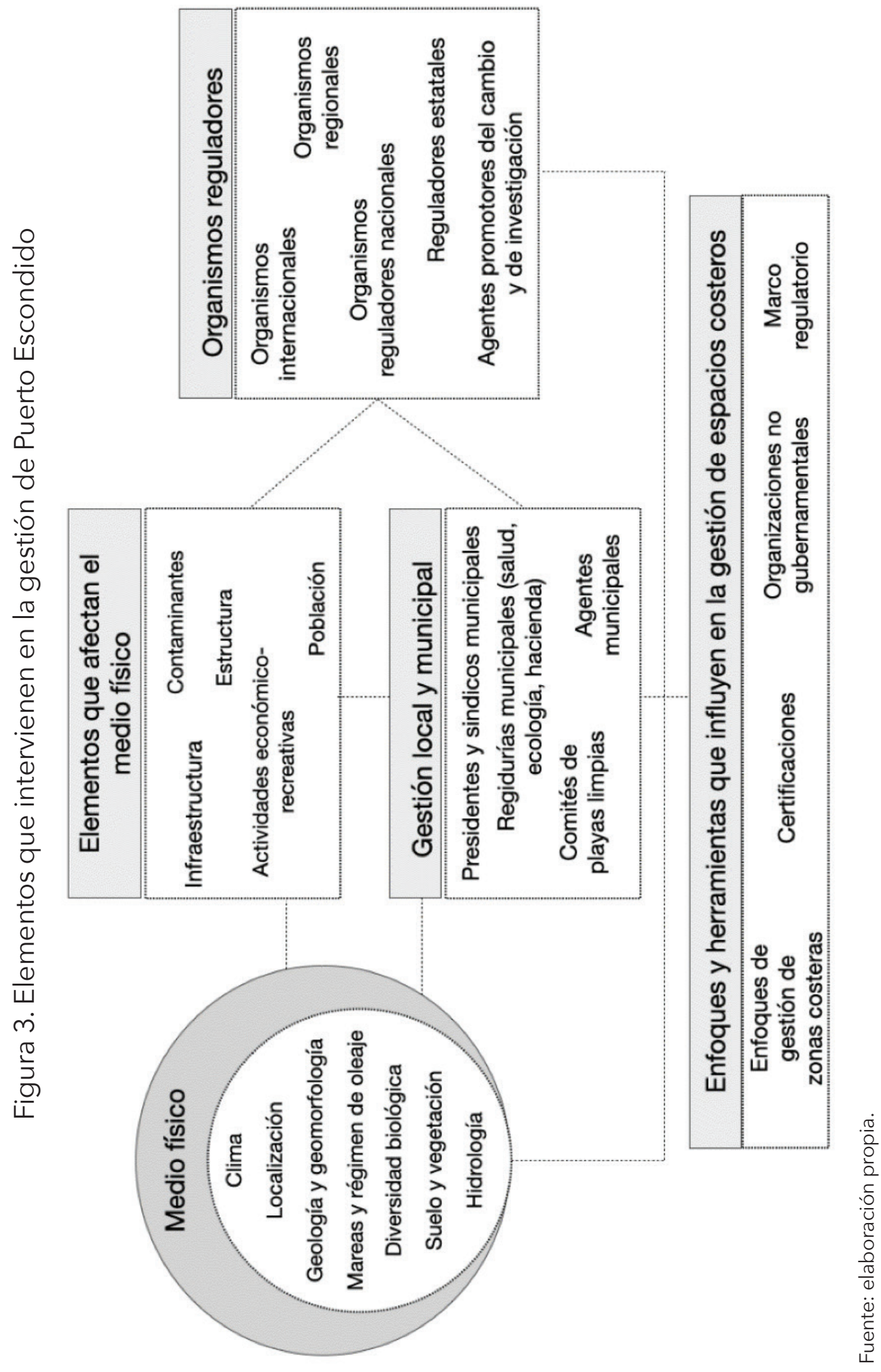


b) Elementos que afectan el medio físico: el crecimiento poblacional y la actividad turística.

c) Gestión local y municipal: se encargan de vigilar el uso de los recursos, regulan las actividades que se desarrollan en el entorno costero y los contaminantes que de ellas se derivan. Promueven proyectos turístico-recreativos, de saneamiento o de desarrollo económico.

d) Organismos reguladores: se encargan de la vigilancia y de promover programas, proyectos o políticas que influyen en la gestión del entorno.

i. Secretarías de Estado.

ii. Dependencias y órganos federales.

iii.Dependencias estatales y regionales (se incluye el Consejo de Cuenca de la Costa de Oaxaca).

Así mismo la generación de conocimiento por medio de investigadores, proyectos derivados de universidades, activistas, medios de comunicación, también contribuye a regular las actividades del entorno costero.

e) Enfoques y herramientas que influyen en la gestión de espacios costeros (como el $\mathrm{MCl}$ ). Promueven la revisión del marco regulatorio y de las políticas públicas. Además, algunas organizaciones no gubernamentales (ONG) promueven programas de limpieza de playas, proyectos de investigación, incorporación de sistemas de biodigestores que benefician a las playas. Así mismo, las certificaciones promueven la participación social para el ordenamiento de las playas, su saneamiento, la vigilancia de contaminantes en la zona terrestre y la acuática; fomentan la vinculación de los consejos de playas limpias con universidades, el sector privado y el sector público para lograr estos distintivos y su permanencia.

Identificación de las relaciones conflictivas

Siguiendo la MSS, una vez identificados los elementos que influyen en el fenómeno, éstos se agrupan de acuerdo con su grado de influencia y se determinan las relaciones entre dichos elementos. Un grupo corresponde al sistema y el otro a su entorno. Los elementos del sistema son los recursos y los actores que forman parte de la problemática y que dan propósito al sistema. El entorno lo conforman aquellos elementos sobre los que los tomadores de decisiones y los propios componentes del sistema no tienen injerencia, pero cuya presencia lo condicionan o limitan. La representación pictográfica de este conjunto de elementos y de sus relaciones es conocida como visión rica (Checkland, 1999; Wilson, 1990).

Las interacciones entre estos elementos pueden presentarse de diversas formas, pero se reconocen dos tipos de interacción: relaciones sanas y relaciones conflictivas. Las primeras permiten que el sistema cumpla con su propósito, mientras que las segundas limitan o interfieren con dicho propósito, ya sea por un mal funcionamiento o por su ausencia. En PE se identificaron las siguientes relaciones (véase figura 4): 
Tabla 4. Representación pictográfica

\begin{tabular}{|c|c|c|c|c|c|}
\hline Elemento & Icono & Elemento & Icono & Elemento & Icono \\
\hline Población & illo & $\begin{array}{l}\text { Diversidad } \\
\text { biológica }\end{array}$ & & $\begin{array}{l}\text { Organismos } \\
\text { regionales }\end{array}$ & 8 \\
\hline Geomorfología & (1) & $\begin{array}{c}\text { Suelo y } \\
\text { vegetación }\end{array}$ & (a) & $\begin{array}{c}\text { Reguladores } \\
\text { estatales }\end{array}$ & \\
\hline Hidrología & Hu & Localización & L & $\begin{array}{l}\text { Organismos } \\
\text { reguladores } \\
\text { nacionales }\end{array}$ & \\
\hline Contaminantes & & $\begin{array}{l}\text { Mareas y } \\
\text { régimen de } \\
\text { oleaje }\end{array}$ & drangs & $\begin{array}{c}\text { Organismos } \\
\text { internacionales }\end{array}$ & $\underset{\text { CIMARES }}{20}$ \\
\hline Infraestructura & & $\begin{array}{l}\text { Actividades } \\
\text { económico- } \\
\text { recreativas }\end{array}$ & 㭗盖 & $\begin{array}{l}\text { Organizaciones No } \\
\text { Gubernamentales }\end{array}$ & $\overline{1}$ \\
\hline Estructura & & Clima & 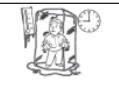 & Certificaciones & \\
\hline $\begin{array}{c}\text { Agentes } \\
\text { promotores } \\
\text { del cambio e } \\
\text { investigación }\end{array}$ & & $\begin{array}{l}\text { Marco } \\
\text { regulatorio }\end{array}$ & 18 & Gestión municipal & 단 \\
\hline $\begin{array}{l}\text { Enfoques de } \\
\text { gestión de } \\
\text { zonas costeras }\end{array}$ & 28 & $\begin{array}{c}\text { Autoridades } \\
\text { locales }\end{array}$ & 藏 & & \\
\hline
\end{tabular}

Fuente: elaboración propia.

a) Sanas. Interacciones que no afectan la gestión de las playas.

b) Relaciones que podrían beneficiar a las playas. Muestran aquella comunicación que debe mejorarse para fortalecer la gestión de este espacio.

c) Relaciones en riesgo. Consideran la vulnerabilidad entre la sinergia, el ambiente y el humano.

d) Relaciones en conflicto. Afectan el ambiente por la actividad antrópica.

La figura 4 muestra, del centro hacia afuera, el medio físico que soporta la actividad turística. Enseguida se muestran los elementos que conforman el sistema en foco que engloba los elementos que influyen de manera directa en la problemática de PE y, por último, se muestra su entorno. Las tablas 5, 6 y 7 aclaran las relaciones en conflicto mostradas en la figura 4. Estas relaciones se conciben en el presente documento con base en la información proporcionada por los CPL involucrados. 


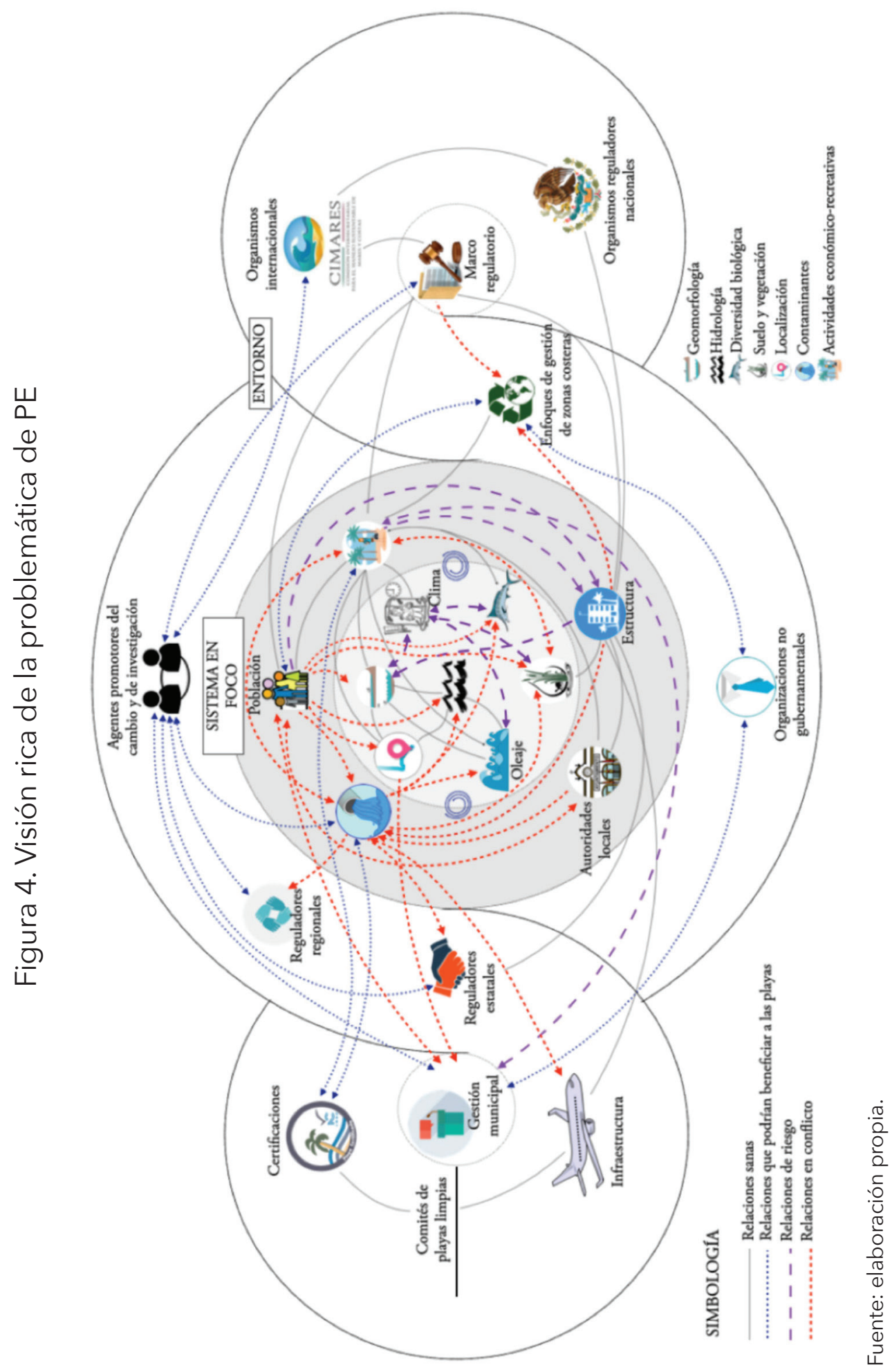


Tabla 5. Relaciones en conflicto

\begin{tabular}{|c|c|c|}
\hline \multicolumn{2}{|c|}{ Elementos } & Característica \\
\hline \multirow[t]{8}{*}{ Población } & Geomorfología & $\begin{array}{c}\text { Los habitantes no están conscientes de la afectación al espacio } \\
\text { que pueden ocasionar actividades no planeadas. }\end{array}$ \\
\hline & $\begin{array}{l}\text { Diversidad } \\
\text { biológica }\end{array}$ & $\begin{array}{c}\text { Se requiere la difusión de información para el cuidado } \\
\text { y protección de la biodiversidad, incluida la marina } \\
\text { y terrestre de las zonas de playas. }\end{array}$ \\
\hline & $\begin{array}{l}\text { Suelo y } \\
\text { vegetación }\end{array}$ & $\begin{array}{c}\text { Los habitantes no conocen el impacto que pueden causar } \\
\text { en el suelo o la vegetación al realizar actividades en las playas, } \\
\text { por lo que no tienen cuidado. }\end{array}$ \\
\hline & Hidrología & Se usan los afluentes como medio de descarga de residuos. \\
\hline & Localización & $\begin{array}{c}\text { Existen discrepancias en la delimitación geográfica de la playa } \\
\text { principal: su jurisdicción se divide en dos municipios, } \\
\text { lo que causa confusión en la población. }\end{array}$ \\
\hline & Contaminantes & $\begin{array}{c}\text { La participación en los programas de limpieza de playas } \\
\text { es heterogénea. }\end{array}$ \\
\hline & $\begin{array}{l}\text { Autoridades } \\
\text { locales }\end{array}$ & $\begin{array}{l}\text { Aunque hay progresos, falta capacitación para el cuidado de las } \\
\text { playas. A su vez, la población debe incrementar esta demanda. }\end{array}$ \\
\hline & $\begin{array}{l}\text { Gestión } \\
\text { municipal }\end{array}$ & $\begin{array}{c}\text { Uno de los principales problemas de la gestión de playas de } \\
\text { Puerto Escondido es que la población tiene discrepancia sobre } \\
\text { a quién corresponde la jurisdicción en la playa Principal } \\
\text { y el Adoquín. La división municipal complica la regulación } \\
\text { de responsabilidades. }\end{array}$ \\
\hline $\begin{array}{l}\text { Autoridades } \\
\text { locales }\end{array}$ & Contaminantes & $\begin{array}{c}\text { Las autoridades locales no pueden procesar los contaminantes, } \\
\text { por lo que requieren el apoyo de otras autoridades. }\end{array}$ \\
\hline Localización & $\begin{array}{l}\text { Gestión } \\
\text { municipal }\end{array}$ & $\begin{array}{c}\text { Se ha concluido que el factor geográfico y político no es la vía } \\
\text { para establecer un esquema de gestión de PE, } \\
\text { debido a que aún permea la discrepancia socio-política } \\
\text { sobre la jurisdicción del espacio. }\end{array}$ \\
\hline \multirow[t]{2}{*}{$\begin{array}{l}\text { Actividades } \\
\text { económico- } \\
\text { recreativas }\end{array}$} & $\begin{array}{l}\text { Suelo y } \\
\text { vegetación }\end{array}$ & $\begin{array}{l}\text { Las actividades económico-recreativas dependen } \\
\text { de la calidad del suelo y de la vegetación, pero no se han } \\
\text { presentado prácticas sustentables en su desarrollo. }\end{array}$ \\
\hline & Contaminantes & $\begin{array}{l}\text { Los establecimientos generan desechos. Aunque se comienzan } \\
\text { capacitaciones, aún no se tienen buenas prácticas en todos los } \\
\text { negocios. La contaminación cercana a Playa Marinero } \\
\text { afecta la certificación como playa limpia de Zicatela. }\end{array}$ \\
\hline \multirow[t]{2}{*}{$\begin{array}{l}\text { Estructura } \\
\text { turística }\end{array}$} & Contaminantes & $\begin{array}{l}\text { Las construcciones urbanas y turísticas no se desarrollaron bajo } \\
\text { esquemas de buenas prácticas, por lo que generan } \\
\text { contaminantes. } \\
\text { La zona conocida como La Lagunita se contamina } \\
\text { por la descarga de aguas residuales, lo que pone en riesgo } \\
\text { las playas vecinas, como Zicatela y Principal. }\end{array}$ \\
\hline & $\begin{array}{l}\text { Enfoques de } \\
\text { gestión de } \\
\text { zonas costeras }\end{array}$ & $\begin{array}{l}\text { La estructura no coincide con los requerimientos de } \\
\text { sustentabilidad de los enfoques de gestión de zonas costeras. }\end{array}$ \\
\hline $\begin{array}{l}\text { Marco } \\
\text { regulatorio }\end{array}$ & $\begin{array}{l}\text { Enfoques } \\
\text { de gestión de } \\
\text { zonas costeras }\end{array}$ & $\begin{array}{c}\text { Pese a que ya se considera la integración, } \\
\text { aún se observan competencias fragmentadas. } \\
\text { Además, el hecho de que las playas sean zonas federales } \\
\text { dentro de demarcaciones municipales atrasa la gestión } \\
\text { y manejo de recursos. }\end{array}$ \\
\hline
\end{tabular}




\begin{tabular}{|c|c|c|}
\hline \multirow[t]{7}{*}{ Contaminantes } & $\begin{array}{l}\text { Organismos } \\
\text { reguladores } \\
\text { regionales }\end{array}$ & \multirow{2}{*}{$\begin{array}{l}\text { La gestión regional y estatal de las zonas costeras no ha sido } \\
\text { suficiente para afrontar los problemas de contaminación que } \\
\text { presentan las playas de PE, sobre todo en materia de descarga } \\
\text { de aguas residuales. }\end{array}$} \\
\hline & $\begin{array}{l}\text { Organismos } \\
\text { reguladores } \\
\text { estatales }\end{array}$ & \\
\hline & Hidrología & \multirow{4}{*}{$\begin{array}{c}\text { Los afluentes hidrológicos, la diversidad biológica, } \\
\text { el suelo y las aguas marinas se ven afectados por los } \\
\text { contaminantes (residuos sólidos y aguas residuales). } \\
\text { Este problema se agrava por la ausencia de claridad } \\
\text { en la división del trabajo y en el establecimiento } \\
\text { de responsabilidades en la zona del lindero } \\
\text { entre los municipios. }\end{array}$} \\
\hline & $\begin{array}{c}\text { Suelo y } \\
\text { vegetación }\end{array}$ & \\
\hline & $\begin{array}{l}\text { Diversidad } \\
\text { biológica }\end{array}$ & \\
\hline & $\begin{array}{l}\text { Mareas y } \\
\text { régimen de } \\
\text { oleaje }\end{array}$ & \\
\hline & Infraestructura & $\begin{array}{l}\text { La infraestructura genera contaminantes, } \\
\text { a la vez que no es suficiente para procesar } \\
\text { los residuos generados en PE, lo que afecta las playas. }\end{array}$ \\
\hline
\end{tabular}

Fuente: elaboración propia con base en información proporcionada por los CPLSPM y CPLSMC.

Tabla 6. Relaciones de riesgo

\begin{tabular}{|c|c|c|}
\hline \multicolumn{2}{|c|}{ Elementos } & Característica \\
\hline Población & Estructura & $\begin{array}{c}\text { El incremento poblacional sería un riesgo para la } \\
\text { zona bajo estudio, pues aumentaría la demanda } \\
\text { de estructura urbana y, tal vez, la recreativa. }\end{array}$ \\
\hline \multirow[t]{2}{*}{$\begin{array}{l}\text { Actividades } \\
\text { económico- } \\
\text { recreativas }\end{array}$} & Estructura & $\begin{array}{c}\text { El incremento de la demanda y oferta turística } \\
\text { suponen la creación de mayor estructura, lo cual, } \\
\text { de no hacerse bajo un esquema sustentable y de } \\
\text { planeación, podría afectar las playas. }\end{array}$ \\
\hline & $\begin{array}{l}\text { Gestión } \\
\text { municipal }\end{array}$ & $\begin{array}{l}\text { Las autoridades pueden canalizar las necesidades } \\
\text { del sector económico de Puerto Escondido a fin } \\
\text { de garantizar la calidad ambiental y turística del } \\
\text { destino. Si el destino crece, las necesidades } \\
\text { también. Algunas necesidades son: saneamiento, } \\
\text { capacitación en la prestación de servicios turísticos } \\
\text { y en el manejo de los residuos, estructura, } \\
\text { infraestructura y herramientas. }\end{array}$ \\
\hline $\begin{array}{l}\text { Estructura } \\
\text { turística }\end{array}$ & Geomorfología & $\begin{array}{c}\text { El crecimiento de la estructura turística podría } \\
\text { modificar las condiciones geomorfológicas } \\
\text { de las playas. }\end{array}$ \\
\hline \multirow[t]{4}{*}{ Clima } & Geomorfología & \multirow{4}{*}{$\begin{array}{c}\text { Un cambio en las condiciones climáticas podría } \\
\text { originar un cambio en la morfología de las playas, } \\
\text { en la biodiversidad, en las condiciones del suelo y } \\
\text { la vegetación, e incluso en las corrientes marinas } \\
\text { y en la calidad del oleaje, lo cual repercutiría en el } \\
\text { paisaje turístico y en las actividades económicas } \\
\text { que se pueden desarrollar en PE. }\end{array}$} \\
\hline & Suelo y vegetación & \\
\hline & $\begin{array}{l}\text { Diversidad } \\
\text { biológica }\end{array}$ & \\
\hline & $\begin{array}{c}\text { Mareas y régimen } \\
\text { de oleaje }\end{array}$ & \\
\hline
\end{tabular}

Fuente: elaboración propia con base en información proporcionada por los CPLSPM y CPLSMC. 
Tabla 7. Relaciones que podrían mejorar las playas

\begin{tabular}{|c|c|c|}
\hline \multicolumn{2}{|c|}{ Elementos } & Característica \\
\hline Población & $\begin{array}{c}\text { Enfoques de } \\
\text { gestión de zonas } \\
\text { costeras }\end{array}$ & $\begin{array}{c}\text { La participación de la población no es } \\
\text { homogénea, por lo que requiere fortalecer } \\
\text { la proactividad. Esto, de acuerdo con los } \\
\text { enfoques integrales de gestión de playas, } \\
\text { permitiría una integración en beneficio del } \\
\text { saneamiento y cuidado de las playas. } \\
\text { Además, su aplicación práctica fortalecería } \\
\text { o refutaría la teoría. }\end{array}$ \\
\hline \multirow[t]{2}{*}{ Certificaciones } & $\begin{array}{l}\text { Actividades } \\
\text { económico- } \\
\text { recreativas }\end{array}$ & \multirow{2}{*}{$\begin{array}{l}\text { Las certificaciones se han convertido } \\
\text { en un incentivo para mejorar la calidad } \\
\text { de los servicios y tener los mejores sistemas de } \\
\text { tratamiento y vigilancia de residuos, por lo que, } \\
\text { como estrategia para mejorar la gestión de } \\
\text { playas, se deben fortalecer e incrementar. }\end{array}$} \\
\hline & Contaminantes & \\
\hline \multirow{6}{*}{$\begin{array}{c}\text { Agentes } \\
\text { promotores } \\
\text { del cambio } \\
\text { e investigación }\end{array}$} & Contaminantes & \multirow{6}{*}{$\begin{array}{c}\text { Por un lado, se requiere mayor número de } \\
\text { investigaciones sobre los elementos que afectan } \\
\text { la calidad de la playa y sobre aquellos aspectos } \\
\text { que sirvan para la toma de decisiones. Por otro } \\
\text { lado, se requiere impulsar la vinculación entre } \\
\text { el área académica y la aportación científica } \\
\text { y de investigación, tanto de organizaciones } \\
\text { no gubernamentales, como de universidades } \\
\text { y centros de investigación, para lograr que los } \\
\text { conocimientos generados sean adoptados por } \\
\text { los gestores de la zona costera, tanto } \\
\text { a nivel local como a nivel regional, estatal } \\
\text { y federal. Con ello se fortalecería } \\
\text { la gestión local de playas y la formulación } \\
\text { de las políticas públicas. }\end{array}$} \\
\hline & $\begin{array}{l}\text { Marco } \\
\text { regulatorio }\end{array}$ & \\
\hline & $\begin{array}{l}\text { Organismos } \\
\text { reguladores } \\
\text { nacionales }\end{array}$ & \\
\hline & $\begin{array}{l}\text { Organismos } \\
\text { reguladores } \\
\text { regionales }\end{array}$ & \\
\hline & $\begin{array}{l}\text { Organismos } \\
\text { reguladores } \\
\text { estatales }\end{array}$ & \\
\hline & $\begin{array}{l}\text { Gestión } \\
\text { municipal }\end{array}$ & \\
\hline
\end{tabular}

Fuente: elaboración propia con base en información proporcionada por los CPLSPM y CPLSMC.

En resumen, se pueden citar, como principales conflictos detectados en PE, la generación de contaminantes y su falta de tratamiento, la carencia de un ordenamiento tanto de estructura como de actividades antrópicas y la heterogénea participación de la comunidad.

Sin embargo, en otras playas la integración de la sociedad ha repercutido en avances significativos. Por ejemplo, en 2014 y en 2016 la playa de Bacocho y la de Zicatela lograron respectivamente la certificación mexicana de "playa limpia". Estos reconocimientos fortalecieron el interés de la sociedad civil para participar en acciones de saneamiento.

A principios de 2018, con el apoyo de la gerencia operativa del CPLSMC, estas acciones de participación social se extendieron a las playas de Puerto Angelito, Carrizalillo y Manzanillo con la creación de comités de saneamiento, promoción 
turística y de servicios náuticos. Más tarde, en 2019, se creó el Consejo Turístico y Empresarial para el Desarrollo Integral y Sustentable de la Costa, a fin de promover un uso sustentable de los recursos y fortalecer la promoción turística de PE. La estructura de saneamiento que se ha conformado en este destino se representa en la figura 5.

Figura 5. Estructura de la organización social para el saneamiento de las playas de PE

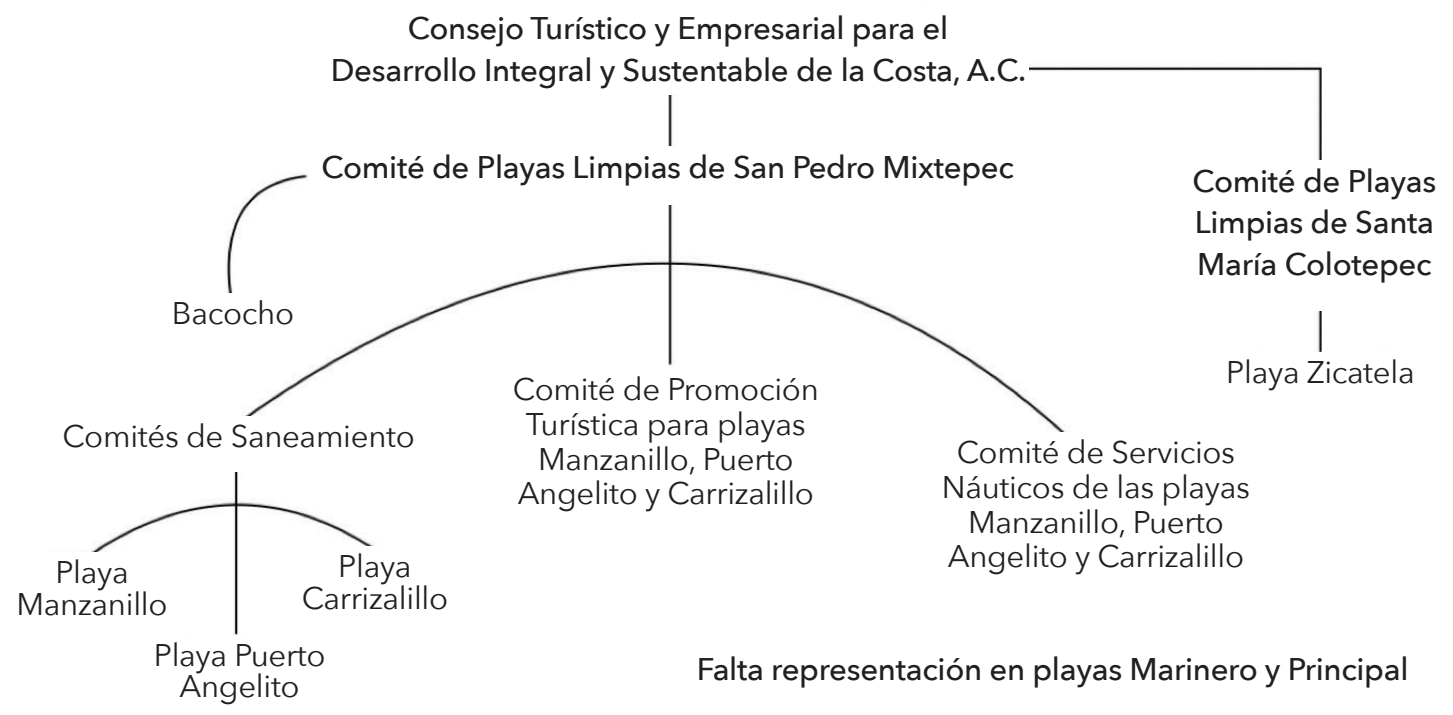

Fuente: elaboración propia.

En las playas donde hay organización social, se han logrado acciones de mejora respecto a saneamiento y coordinación. Las principales actividades que se han implementado son: limpieza mensual de playas y zonas adyacentes, barrido diario con rastrillo en áreas concesionadas, instalación de botes de basura y la gestión de recursos. De acuerdo con la población y los CPL, esto ha generado el regreso de especies, como mapaches, tortugas, crustáceos y cangrejos que, reportan, habían disminuido en los últimos cinco años; se han reducido los residuos sólidos, como plásticos y vidrios en las playas y se ha observado aceptación de los visitantes hacia acciones ambientales. Incluso se considera que la demanda turística ha aumentado.

No obstante los beneficios obtenidos, se han reportado algunas limitantes. Por ejemplo, aún no se logra la priorización de las problemáticas identificadas por la sociedad civil como parte de la agenda de los gobiernos en turno. Hace falta el ordenamiento costero y náutico, pero esto requiere la participación de las autoridades. Los beneficios económicos obtenidos por el cobro de licencias 
y permisos de operación del uso de la zona federal mexicana, lo administran las autoridades, por lo que la sociedad civil está limitada en recursos. Se evidencia una desvinculación entre el gobierno y la actuación local. Las acciones de participación local no han sido extendidas a todas las playas de PE.

\section{Discusión}

El turismo de litoral requiere procesos innovadores que permitan hacer frente a los cambios operados por la demanda turística, la aparición de nuevos tipos de turismo, el incremento de destinos competidores, los cambios tecnológicos y la atención hacia la presión ambiental (Soares, Ivars y Gândara, 2015), por lo cual la adecuada gestión costera es un tema central para mantener el beneficio de la actividad turística en estos entornos.

En la búsqueda de un mejor aprovechamiento de los recursos costeros, se ha promovido el $\mathrm{MCl}$ como guía para la coordinación, la integración y el aprendizaje continuo. Sin embargo, Derrick y Xue (2017), Farinós y Cortés (2010) y Portman et al. (2012) argumentan que alcanzar dicha integralidad ha sido díficil debido a la falta de coordinación y, sobre todo, por la carente integración local.

De acuerdo con Jiménez, Tejeida, Coria, Sánchez y Núñez (2017) y Jiménez et al., (2019), la participación local es un aspecto importante para lograr el éxito de una política de $\mathrm{MCl}$. Al respecto, Chapin y Knapp (2015), Mizuta y Vlachopoulou (2017) y Sakurai, Ota y Uehara (2017) exponen que los lugareños son los principales responsables del uso de los recursos costeros, por lo cual deben involucrarse en la toma de decisiones a fin de concretar la política vigente de cada país y mejorar el uso sustentable costero.

$\mathrm{La}$ adopción del enfoque de $\mathrm{MCl}$ a la política mexicana ha repercutido de manera significativa en mejoras a su gestión costera. Entre los aciertos de integralidad, se puede citar la creación de la Comisión Intersecretarial de Mares y Costas (CIMARES), que se ha encargado de promover mejoras a la política en cuestión a partir de la coordinación institucional a fin de evitar duplicidad de funciones y de armonizar la gestión a beneficio de todos los involucrados en el entorno costero mexicano.

Además de esta coordinación institucional, los avances hacia un $\mathrm{MCl}$ en México se enfocan en la vinculación del gobierno con la sociedad. La evolución de la política mexicana de mares y costas y de su marco normativo ha facilitado el interés de la población en participar en programas como el de Playas Limpias y en las certificaciones de playas.

PE es un ejemplo de ello. El trabajo de los CPL en este destino ha fomentado la participación de la sociedad, con lo cual se han conseguido avances significativos, como: certificaciones de dos playas como "playas limpias", establecimiento de jornadas de limpieza, unión de la población para conservar el distintivo, vinculación con universidades para el desarrollo de investigaciones, gestión organizada de recursos, asambleas de discusión y vinculación con representantes de otras playas del entorno costero de Oaxaca. 
En este sentido, PE se ha convertido en un destino costero que, a nivel micro, ha impulsado los principios del $\mathrm{MCl}$ y de la política mexicana de mares y costas. Sin embargo, los avances en su gestión han sido parciales debido a que la participación social ha sido heterogénea. En las playas donde se ha logrado la coordinación social, la gente se ha enfrentado a las deficiencias burocráticas de la gestión costera: la múltiple participación de instituciones en la autorización y distribución de recursos limita la actuación social.

La integración que propone el $\mathrm{MCl}$ es intersecretarial y la política mexicana de mares y costas considera la integración social en la toma de decisiones, pero no es clara en la forma en que podrá integrarla. La política de costas en México menciona las actividades y responsabilidades gubernamentales para fomentar una gestión y uso sustentable de este recurso. Pero deja de lado la actuación local, que podría ser la base de operación para eficientar esta política, lo que, además, ayudaría a concientizar a la comunidad sobre el valor de mantener la salud de los ecosistemas costeros y marinos.

Para avanzar hacia un nivel de integración mayor, se debe partir de una integración local que vaya más allá de la comprensión del destino como un mero recurso turístico. El método sistémico permite transitar de esta visión utilitarista hacia una mejor comprensión de la relación entre el hombre y la naturaleza. En este contexto, es importante que los actores principales participen en el proceso de regulación costera, tanto en su aspecto ambiental como económico.

Los resultados obtenidos permiten observar que, al fortalecer la gestión de una playa mediante la participación de la comunidad, se motiva la participación en playas aledañas, lo cual fortalece los mecanismos de colaboración procurando un efecto viable de co-manejo de playas como base de un $\mathrm{MCl}$. En este sentido, la implementación de políticas de gestión de zonas costeras parece más factible, pues tiene el soporte gubernamental apoyado en la participación local.

\section{Conclusiones}

Los territorios costeros de uso turístico son sistemas derivados de construcciones sociales. Sin embargo, en los entornos donde no se ha dado una sana relación entre hombre y naturaleza, se han generado perturbaciones que han alterado la calidad ambiental de las playas.

La revisión de la literatura muestra que enfoques como el de manejo costero integrado han tomado relevancia en los países costeros para mejorar la gestión de estos espacios. La distribución de responsabilidades de un espacio tan amplio y complejo como las costas implica incorporar diversas instituciones, lo que podría generar conflictos si no se tiene un adecuado control de éstas. Por lo anterior, se ha considerado como alternativa plantear la coordinación e integración interinstitucional como base de las políticas para mejorar la gestión de los espacios costeros.

Los recursos del gobierno no son suficientes para afrontar los retos de una gestión sustentable de costas, por lo que la integración propuesta requiere la participación social y no sólo la institucional. 
En este sentido, se requieren mecanismos que promuevan darle voz y voto a los usuarios de estas playas, los concesionarios y los voluntarios que deseen colaborar. La aplicación de la MSS a un contexto como el expuesto en este trabajo promueve un proceso de aprendizaje y crea las bases para establecer una alternativa que complemente la gestión de playas. El desarrollo de esta metodología provee a los participantes espacios y medios para expresar su visión, su experiencia y su conocimiento. La aplicación de la MSS al contexto de PE permitió detectar discrepancias entre las necesidades de saneamiento de la comunidad y los planes y programas ejecutados por el sector gubernamental.

Aunque el gobierno busca la creación y la promoción de planes, programas y políticas integrales, su aplicación es nominativa y se sigue priorizando el enfoque sectorial. La sociedad civil se ha limitado a la implementación de acciones de saneamiento, pero aún no se desarrollan los mecanismos adecuados para su participación en la toma de decisiones que sean incorporadas a la planeación gubernamental. La integración de los actores es parcial: se ha dado sólo en algunas playas. Si se pretende lograr una vinculación entre gobierno y sociedad, se requiere el involucramiento de un mayor número de personas.

En el marco de las consideraciones anteriores, el presente trabajo propone la integración local como mecanismo para avanzar hacia el cumplimiento de la política de mares y costas mexicanas, a fin de lograr un manejo costero integrado. Se busca poner en evidencia que la autogestión es una opción para que los involucrados en un espacio costero tomen acciones que fomenten el uso responsable de los recursos costeros y sean los principales portavoces de las necesidades que surgen en estos entornos. De esta manera, el gobierno puede ser un coordinador y puede disponer, de manera más eficiente, los recursos para mejorar la calidad ambiental de las playas y, además, conservar los beneficios económicos que éstas proveen.

\section{Referencias}

Alves, B., Rigall, R., Ballester, R., Benavante, J., y Ferreira, O. (2015). Coastal erosion perception and willingness to pay for beach management (Cadiz, Spain). Journal of Coastal Conservation (19), 269-280. Recuperado de https://doi.org/10.1007/s11852-015-0388-6

Avellar, M. de, García, M., y Jara, E. (2014). Procesos de manejo costero integrado en Ecuador y Sri Lanka: una perspectiva de comparación. Revista Intrópica (9), 43-59.

Banco de Desarrollo de América Latina (CAF). (2017). Los ecosistemas marinos son clave para el desarrollo económico de América Latina. Recuperado de https://www.caf.com/es/conocimiento/visiones/2017/04/los-ecosistemas-marinos-son-clave-para-el-desarrollo-economico-de-america-latina/

Barragán, J. M. (2012). Manejo Costero Integrado en Iberoamérica: diagnóstico y propuestas para una nueva política pública. Cádiz: Red Ibermar. 
Bombana, B., Conde, D., y Polette, M. (2016). Gestión de playas urbanas: un análisis comparativo de los procesos de gobernanza de las playas Pocitos (Montevideo, Uruguay) y Central (Balneário Camboriú-SC, Brasil). Desenvolvimento e Meio Ambiente (36), 291-313. Recuperado de https://doi. org/10.5380/dma.v36i0.43858

Calçada de Lamare Leite, F. (2017). La diversificación de la oferta turística como alternativa para minimizar la estacionalidad: el caso de los eventos Balneário Camboriú (Santa Catarina, Brasil). Cuadernos de Turismo (39), 91-112. Recuperado de https://doi.org/10.6018/turismo.39.290451

Cappucci, S., Scarcella, D., Rossi, L., y Taramelli, A. (2011). Integrated coastal zone management at Marina di Carrera Harbor: sediment management and policy making. Ocean \& Coastal Management (54), 277-289. Recuperado de https://doi.org/10.1016/j.ocecoaman.2010.12.0 06

Chapin, F. S., y Knapp, C. N. (2015). Sense of place: a process for identifying and negotiating potentially contested visions of sustainability. Environmental Science \& Policy (53), 38-46. Recuperado de https://doi.org/10.1016/j. envsci.2015.04.012

Checkland, P. (1993). Systems Thinking, Systems Practice. Nueva York: John Wiley \& Sons.

Checkland, P. (1999). Soft Systems Methodology: A 30-Year Retrospective. Nueva York: John Wiley \& Sons.

Chen, C., y Ning, T. (2016). Management priorities and carrying capacity at a high-use beach from tourists' perspectives: a way towards sustainable beach tourism. Marine Policy (74), 213-219. Recuperado de https://doi.org/10.1016/j.marpol.2016.09.030

Comisión Intersecretarial para el Manejo Sustentable de Mares y Costas (ClMARES). (2012a). CIMARES Actividades 2008-2012, síntesis ejecutiva. Recuperado de http://www.semarnat.gob.mx/sites/default/files/documentos/ ordenamiento/cimares/cimares_informefinal2008-2012.pdf

Comisión Intersecretarial para el Manejo Sustentable de Mares y Costas (CIMARES). (2012b). Política Nacional de Mares y Costas de México.

Comisión Intersecretarial para el Manejo Sustentable de Mares y Costas (CIMARES). (2018). Acuerdo mediante el cual se expide la Política Nacional de Mares y Costas de México. Recuperado de https: //www.dof.gob.mx/nota_detalle.php?codigo $=5545511 \&$ fecha $=30 / 11 / 2018$

Comisión Nacional del Agua. (2010). Playas limpias. Recuperado de http:/ / www. conagua.gob. $\mathrm{mx} /$ Contenido. aspx?n1=4\&n2=45\&n3=45\%0D

Comisión Nacional del Agua. (2018). Programa Playas Limpias, Agua y Ambiente Seguros (Proplayas). Recuperado de https://www.gob.mx/conagua/acciones-y-programas/programa-playas-limpias-agua-y-ambiente-seguros-proplayas

Comité de Información SECTUR. (2013). Oficio CI/203/2013, 00021004513.

Congreso General de los Estados Unidos Mexicanos. (2004). Ley General de Bienes Nacionales. México.

Consejo Nacional de Población. (2018). La situación demográfica de México 2017. Ciudad de México: CONAPO. 
Derrick, S., y Xue, X. (2017). Public sector governance in Cameroon: A valuable opportunity or fatal aberration from the Kribi Campo integrated coastal management? Ocean \& Coastal Management (138), 83-92. Recuperado de https://doi.org/10.1016/j.ocecoaman.2017.01.006

Farinós, J., y Cortés, M. C. (2010). Planificación y gobernanza del espacio litoral valenciano. Todavía lejos de una verdadera GIZC. Cuadernos de Geografía (88), 141-170.

Fernandes Pereira, T., Barra Montevechi, J. A., Carvalho Miranda, R. de, y Daniel Friend, J. (2015). Integrating soft systems methodology to aid simulation conceptual modeling. International Transactions in Operational Research (22), 265-285. Recuperado de https://doi.org/10.1111/itor.12133

Grupo de Expertos sobre los Aspectos Científicos de la Protección del Medio Marino (GESAMP). (1969). Report of the first session. Joint IMCO/FAQ/UNESCO/ WMO Group of Experts on The Scientific Aspects of Marine Pollution. Londres.

Grupo de Expertos sobre los Aspectos Científicos de la Protección del Medio Marino (GESAMP). (1999). Informes y estudios No. 61 La contribución de la ciencia al manejo costero integrado. Roma: Organización de las Naciones Unidas para la Agricultura y la Alimentación.

Instituto Nacional de Estadística y Geografía (INEGI). (2018). Sistema Automatizado de Información Censal (SAIC).

Instituto Nacional de Estadística y Geografía (INEGI). (2019). Censos y Conteos de Población y Vivienda. Recuperado de https://www.inegi.org.mx/programas/ccpv/cpvsh/default.html

Jackson, M. (2003). Systems Thinking: Creative Holism for Managers. Londres: John Wiley \& Sons.

Jiménez-Arenas, O. L., Tejeida-Padilla, R., Coria-Páez., A. L., Sánchez-García, J. Y., y Núñez-Ríos, J. E. (2017). Tourist beach management, a perspective from the Systems Thinking. En Proceedings of the 61st Meeting of the International Society for the Systems Sciences. Recuperado de http://journals. isss.org/index.php/proceedings61st/article/view/3222/1074

Jiménez Arenas, O. L., Tejeida Padilla, R., Sáenz Pardo, J. R., y Oliva Aguilar, V. R. (2019). Hacia una autogestión sustentable de playas turísticas desde un Enfoque Sistémico. JAINA Costas y Mares ante el Cambio Climático, 1(1), 41-58. Recuperado de https://doi.org/10.26359/52462.0319

Lozoya, J. P., Sardá, R., y Jiménez, J. A. (2014). Users expectations and the need for differential beach management frameworks along the Costa Brava: urban vs. natural protected beaches. Land Use Policy (38), 397-414. Recuperado de https://dx.doi.org/10.1016/j.landusepol.2013.12.001

Mizuta, D. D., y Vlachopoulou, E. I. (2017). Satoumi concept illustrated by sustainable bottom-up initiatives of Japanese Fisheries Cooperative Associations. Marine Policy (78), 143-149. Recuperado de https://doi.org/10.1016/j.marpol.2017.01.020

Montaño, A., Pérez, J. C., y O, V. de la. (2014). Reposicionamiento para destinos turísticos consolidados: el caso de Los Cabos, México. Cuadernos de Turismo (33), 271-295. 
Muñoz Sevilla, N. P. , y Le Bail, M. (2017). Latin American and Caribbean regional perspective on ecosystem based management (EBM) of large marine ecosystems goods and services. Environmental Development (22), 9-17. Recuperado de https: //doi.org/10.1016/j.envdev.2017.01.006

Nava Fuentes, J. C., Arenas Granados, P., y Martins, F. C. (2017). Coastal management in Mexico: improvements after the marine and coastal policy publication. Ocean \& Coastal Management (137), 131-143. Recuperado de https://doi.org/10.1016/j.ocecoaman.2016.12.017

Organización para la Cooperación y el Desarrollo Económico (OECD). (2017). Tourism Policy Review of Mexico. París: OECD. Recuperado de https://doi. org/10.1787/9789264266575-en

Organización de las Naciones Unidas para la Educación, la Ciencia y la Cultura (UNESCO). (2017). Manejo costero Integrado. Recuperado de http://www. unesco.org/new/es/office-in-montevideo/natural-sciences/manejo-costero-integrado/

Porter, M. (1982). Estrategia competitiva. México: Grupo Editorial Patria.

Portman, M. E., Steves, L. S., Le, X. Q., y Khan, A. Z. (2012). Improving integration for integrated coastal zone management: an eight country study. Science of the Total Environment (439), 194-201. Recuperado de https:// doi. org/10.1016/j.scitotenv.2012.09.016

Pulido, J., y López, Y. (2016). La cadena de valor del destino como herramienta innovadora para el análisis de la sostenibilidad de las políticas turísticas. El caso de España. Revista Innovar, 26(59), 155-175. Recuperado de https:// doi.org/http://dx.doi.org/10.15446/innovar.v26n59.54369

Ramírez-Gutiérrez, A. G., Cardoso-Castro, P. P., y Tejeida-Padilla, R. (2020). A methodological proposal for the complementarity of the SSM and the VSM for the analysis of viability in organizations. Systemic Practice and Action Research. Recuperado de https://doi.org/10.1007/s11213-020-09536-7

Reis, J., Stojanovic, T., y Smith, H. (2014). Relevance of systems approaches for implementing integrated coastal zone management principles in Europe. Marine Policy (43), 3-12. Recuperado de https://doi.org/10.1016/j.marpol.2013.03.013

Rodríguez, I., Montoya, M. J., y Sánchez, F. (2009). Geographic information systems applied to integrated coastal zone management. Geomorphology (107), 100-105.

Sakurai, R., Ota, T., y Uehara, T. (2017). Sense of place and attitudes towards future generations for conservation of coastal areas in the Satoumi of Japan. Biological Conservation (209), 332-340. Recuperado de https://doi.or$\mathrm{g} / 10.1016 / \mathrm{j}$.biocon.2017.02.041

Sampedro Ávila, G., Ávila Serrano, G., Arredondo García, C., y Espejel Carbajal, I. (2015). Síntesis cualitativa de la investigación en la zona costera de México: contribuciones al fortalecimiento de la evaluación de impacto ambiental (EIA). Investigación Ambiental, 7(1), 25-41.

Sánchez-García, J. Y., Ramírez-Gutiérrez, A. G., Núñez-Ríos, J. E., Cardoso-Castro, P. P., y Rojas, O. G. (2019). Systems thinking approach to sustainable 
performance in RAMSAR sites. Sustainability (Switzerland), 11(22), 1-21. Recuperado de https://doi.org/10.3390/su11226469

Secretaría de la Convención de Ramsar. (2010). Manejo de las zonas costeras: cuestiones concernientes a los humedales y manejo integrado de las zonas costeras. En D. Pritchard (ed.), Manuales Ramsar para el uso racional de los humedales. Gland, Suiza: Secretaría de la Convención de Ramsar.

Secretaría de Medio Ambiente y Recursos Naturales (SEMARNAT). (2018). Programa de playas Limpias. Recuperado de http://apps1.semarnat.gob.mx/ dgeia/gob-mx/playas/resultados.html

Secretaría de Medio Ambiente y Recursos Naturales (SEMARNAT). (2019). Crecimiento poblacional en la zona costera. Recuperado de https://apps1.semarnat.gob.mx:8443/dgeia/indicadores17/conjuntob/indicador/06_biodiversidad/03_oceanicos/6_3_5.html

Secretaría de Turismo de Oaxaca. (2019). Indicadores de la actividad turística, cierre 2018. Oaxaca de Juárez. Recuperado de http://www.sectur.oaxaca. gob.mx/wp-content/uploads/2018/03/01.indicadores-turismo-2017-Cierre-definitivo.pdf

Senado de la República, LXII Legislatura. (2015). Iniciativas con proyecto de decreto por el que se expide la ley general para la gestión integral y sustentable de las costas mexicanas. Ciudad de México. Recuperado de http:/ / www. senado.gob. $\mathrm{mx} /$ index. php? ver $=$ sp\&mn=2\&sm $=2 \& i d=54602$

Soares, J. C., Ivars, J. A., y Gândara, J. M. (2015). La evolución de destinos turísticos litorales consolidados. Análisis comparado de Balneario Camborirú (Brasil) y Benidorm (España). Anales de Geografía, 35(2), 432-455.

Tejeida Padilla, R., Cruz Coria, E., y Briones Juárez, A. (2016). Sistémica y turismo. México: Porrúa.

Tikkanen, J., Hujala, T., y Kurttila, M. (2016). Potentials of collaborative decision support methodologies to enhance reconciliation of competing forest uses-An action research on Regional Forest Programme in Finland. Land Use Policy (55), 61-72.

Uehara, T., y Mineo, K. (2017). Regional sustainability assessment framework for integrated coastal zone management: Satoumi, ecosystem services approach, and inclusive wealth. Ecological Indicators (73), 716-725. Recuperado de https://doi.org/10.1016/j.ecolind.2016.10.031

Uehara, T., Niu, J., Chen, X., Ota, T., y Nakagami, K. (2016). A sustainability assessment framework for regional-scale integrated coastal zone management (ICZM) incorporating inclusive wealth, Satoumi, and ecosystem services science. Sustainabilty Science (11), 801-812. Recuperado de https: / / doi. org/10.1007/s11625-016-0373-5

Veléz, L., Reyes, K. L., Rojas, D., Calderón, M. A., Cruz, J. K., y Arcos, J. L. (2014). Riesgo potencial de parásitos zoonóticos presentes en heces caninas en Puerto Escondido, Oaxaca. Salud Pública de México, 56(6), 625-630.

Wang, W., Lui, W., y Mingers, J. (2015). A systemic method for organisational stakeholder identification and analysis using soft systems methodology (SSM). European Journal of Operational Research (246), 562-574. Recuperado de https://doi.org/http://dx.doi.org/10.1016/j.ejor.2015.05.014 
Wilson, B. (1990). System: Concepts, Metodologies and Applications. Nueva Delhi: John Wiley \& Sons.

Yáñez-Arancibia, A., Day, J. W., y Reyes, E. (2013). Understanding the coastal ecosystem-based management approach in the Gulf of Mexico. Journal of Coastal Research (63), 244-262. Recuperado de https://doi.org/10.2112/ SI63-018.1 